\title{
Melhoria da qualidade do leite a partir da implantação de boas práticas de higiene na ordenha em 19 municípios da região central do Paraná
}

\section{Milk quality improvement after implantation of good manufacturing practices in milking in 19 cities of the central region of Paraná}

\author{
Vitória Maria Vallin ${ }^{1}$; Vanerli Beloti ${ }^{*}$; Ana Paula Pavão Battaglini ${ }^{3}$; \\ Ronaldo Tamanini ${ }^{4}$; Rafael Fagnani ${ }^{4}$; Henrique Lopes da Angela ${ }^{3}$; \\ Livia Cavaletti Corrêa da Silva ${ }^{4}$
}

\begin{abstract}
Resumo
O setor leiteiro brasileiro apresenta problemas de eficiência produtiva e de qualidade da matéria-prima e, por isso, perde em competitividade. A má qualidade do leite cru está relacionada a fatores como deficiências no manejo e higiene da ordenha, índices elevados de mastite, manutenção e desinfecção inadequadas dos equipamentos, refrigeração ineficiente ou inexistente e mão de obra desqualificada, entre outros. O objetivo deste trabalho foi avaliar a eficiência da implantação de Boas Práticas na ordenha na ordenha, simples e baratas, que pudessem ser facilmente introduzidas pelos produtores de leite. Os parâmetros de qualidade considerados foram a contagem de células somáticas (CCS), indicativo de sanidade da glândula mamária, e a contagem bacteriana total (CBT), indicativo de higiene de ordenha. Foram analisadas 46 amostras de leite cru de 19 municípios da região central do Paraná, sendo $32(69,57 \%)$ de propriedades com ordenha manual e $14(30,43 \%)$ com ordenha mecânica. Após a implantação das práticas houve uma redução média de $87,90 \%$ na CBT nas propriedades com ordenha manual e $86,99 \%$ nas propriedades com ordenha mecânica. Com relação a CCS, a redução média foi de $33,94 \%$ em propriedades com ordenha manual e $51,85 \%$ em propriedades com ordenha mecânica. As práticas implantadas se mostraram eficientes nos diferentes sistemas de produção.

Palavras-chave: Qualidade do leite, boas práticas na ordenha, contagem bacteriana total, contagem de células somáticas
\end{abstract}

\begin{abstract}
The milk production in Brazil presents efficiency and quality problems concerning the raw material, reducing its competitiveness. The poor quality of raw milk is associated with faults in handling and milking hygiene conditions, high indices of mastitis, inadequate maintenance and disinfection of the equipment, inefficient or inexistent refrigeration, disqualified workforce, among others. The aim of this study was to evaluate the efficiency of implantation of simple, inexpensive and easily adopted Good Manufacturing Practices (GMP) on dairy farms. Quality parameters researched were total bacterial

1 Instituto Paranaense de Assistência Técnica e Extensão Rural - EMATER - PR

2 Docente do Departamento de Medicina Veterinária Preventiva, UEL, Londrina PR. Laboratório de Inspeção de Produtos de Origem Animal, Departamento de Medicina Veterinária Preventiva, Universidade Estadual de Londrina. Caixa Postal 6001, CEP 86051-990, Londrina, PR, Brasil. Tel.: (43) 3371 4708. E-mail: neli@sercomtel.com.br; lipoa.uel@gmail.com

3 Médica(o) Veterinária(o) Residente do Laboratório de Inspeção de Produtos de Origem Animal, DMVP, CCA, UEL, Londrina

4 Programa de Pós Graduação em Ciência Animal (Sanidade Animal) da Universidade Estadual de Londrina, Londrina PR.
\end{abstract} PR.

* Autor para correspondência 
count (TBC) and somatic cell count (SCC), which indicates respectively milking hygiene and mammary gland health. Forty six raw milk samples from 19 cities of the central region of Paraná were analyzed, among them, $32(69,57 \%)$ had manual milking and $14(30,43 \%)$ mechanic milking. The implantation of GMP resulted in average reduction of $87,90 \%$ to TBC on manual milking farms and $86,99 \%$ on mechanic milking farms. Regarding SCC, the average reduction was $33,94 \%$ in manual milking farms and $51,85 \%$ in mechanics milking farms. The implemented practices had shown efficient in all of the studied conditions of production and installations.

Key words: Milk quality, GMP, total bacterial count, somatic cell count

\section{Introdução}

Segundo o Instituto Brasileiro de Geografia e Estatística - IBGE (2007), a produção de leite no Brasil cresceu $69,4 \%$ no período compreendido entre os anos de 1990 e 2005, passando de um volume total de 14,5 bilhões para 24,6 bilhões de litro/ano. Em termos percentuais, a região Norte foi a que apresentou o crescimento mais expressivo, com uma variação de $214 \%$ de crescimento da produção. A região Sul merece destaque com o terceiro maior crescimento da produção (101\%), ficando acima da média nacional. No Estado do Paraná, a produção média de leite apresentou um crescimento no volume de $117 \%$.

Apesar dos dados animadores de produção, o setor leiteiro brasileiro apresenta problemas de eficiência produtiva e de qualidade da matériaprima e, por isso, perde em competitividade (RIBEIRO; STUMPF JÚNIOR; BUSS, 2000). No Brasil, o leite in natura apresenta, em geral, altas contagens de microrganismos aeróbios mesófilos e coliformes, indicando deficiência na higiene da produção (BELOTI et al., 1999; BUENO et al., 2004; CORDEIRO; CARLOS; MARTINS, 2002; FREITAS et al., 2002; SANTANA; BELOTI; BARROS, 2001).

A má qualidade do leite cru e por conseqüência, dos leites pasteurizado e esterilizado, assim como de derivados, está relacionada a fatores como deficiências no manejo e higiene da ordenha, índices elevados de mastite, manutenção e desinfecção inadequadas dos equipamentos, refrigeração ineficiente ou inexistente e mão de obra desqualificada, entre outros (SANTANA et al., 2001).
Entre os microrganismos indicadores de qualidade, estão os aeróbios mesófilos, que constituem um importante grupo de microrganismos, por incluírem a maioria das bactérias acidificantes do leite, assim como os patógenos (NASCIMENTO; SOUZA, 2002). A contagem e determinação de microrganismos aeróbios mesófilos são de grande importância, sendo sua deteç̧ão e enumeração empregadas tanto para o controle da qualidade do leite, como da eficiência das práticas de sanitização de equipamentos e utensílios durante a produção e beneficiamento do produto (FRANCO; LANDGRAF, 1996).

Santana et al. (2001) evidenciaram que, na propriedade leiteira, as principais fontes de contaminação por aeróbios mesófilos, em ordem decrescente, são a superfície e a água residual dos latões e tanques de expansão e tetos mal higienizados.

Outro importante parâmetro de qualidade, que foi recentemente incluído como requisito para aceitação do leite na indústria, é a contagem de células somáticas (CCS). Células somáticas do leite são, normalmente, células de defesa do organismo que migram do sangue para o interior da glândula mamária, com o objetivo de combater os agentes causadores da mastite, podendo ser, também, células descamadas (PHILPOT; NICKERSON, 1991). Inúmeras são as perdas relacionadas com alta CCS. Reneau (1986) observou perdas significativas na produção quando a CCS encontrava-se acima de 100.000 céls./mL. Machado, Pereira e Sarríes (2000) também verificaram mudanças significativas na gordura do leite quando a CCS encontravase acima de 1 milhão de céls. $/ \mathrm{mL}$, e na proteína 
e lactose quando a CCS encontrava-se acima de 500.000 céls./mL.

O crescimento da produção, com a má qualidade do leite produzido no Brasil e com o aumento da exigência do consumidor por maior segurança alimentar, levou o Ministério da Agricultura, Pecuária e Abastecimento (MAPA) a buscar alternativas para melhorar a qualidade do leite do país. As novas normas de produção leiteira foram publicadas na Instrução Normativa $n^{\circ} 51$ (IN51), de 18 de setembro de 2002, que determinou normas na produção, identidade e qualidade de leites tipos A, B, C, pasteurizado e cru refrigerado, além de regulamentar a coleta de leite cru refrigerado e seu transporte a granel (BRASIL, 2002).

De acordo com a IN51 (BRASIL, 2002), os Estados do Sul, Sudeste e Centro-Oeste devem apresentar para leite cru refrigerado contagem bacteriana total (CBT) máxima de 1 milhão UFC/ $\mathrm{mL}$, com redução gradativa a partir de 2008, com limite para leite de conjunto de $300.000 \mathrm{UFC} / \mathrm{mL}$ em 2011. Para a contagem de células somáticas (CCS) foi estabelecido um padrão de 1 milhão células $/ \mathrm{mL}$, com um máximo de 400.000 cels $/ \mathrm{mL}$ em 2011.

A aplicação de Boas Práticas de Produção (BPP) na bovinocultura de leite é uma alternativa para minimizar os riscos de contaminação nas diferentes etapas do processo de produção. Esses procedimentos são capazes de reduzir a contaminação microbiana e/ ou física do leite. BPP fundamentam-se na exclusão, remoção, eliminação, inibição da multiplicação de microrganismos indesejáveis e/ou corpos estranhos e devem ser implantadas em toda cadeia produtiva.
O objetivo deste trabalho foi avaliar a eficiência da implantação de boas práticas de higiene na ordenha, simples e baratas, e que pudessem ser facilmente introduzidas pelos produtores de leite, nos pontos detectados por Santana et al. (2001) como de maior contaminação.

\section{Material e Métodos}

\section{Características das propriedades}

Durante os anos de 2005 e 2006, em parceria com o Instituto Paranaense de Assistência Técnica e Extensão Rural (EMATER/PR) e a Associação de Paranaense de Criadores de Bovinos da Raça Holandesa (APCBRH), foram selecionadas 46 propriedades de 19 municípios da região central do Paraná, de modo que representassem a produção leiteira da região, com ordenhas do tipo manual e mecânica.

\section{Práticas propostas de higiene na ordenha}

Foram utilizadas práticas de higiene na ordenha testadas e recomendadas pelo Laboratório de Inspeção de Produtos de Origem Animal - LIPOA - da Universidade Estadual de Londrina (Figura 1): desprezo dos três primeiros jatos de leite, predipping direto com solução clorada 750 ppm em caneca sem refluxo, higienização manual vigorosa de baldes, latões e refrigeradores com detergente alcalino clorado $2 \%$ e fibra macia LT Scotch-brite ou similar e inversão dos latões e baldes e inclinação de refrigeradores para escoamento da água residual (FAGAN et al, 2005). 

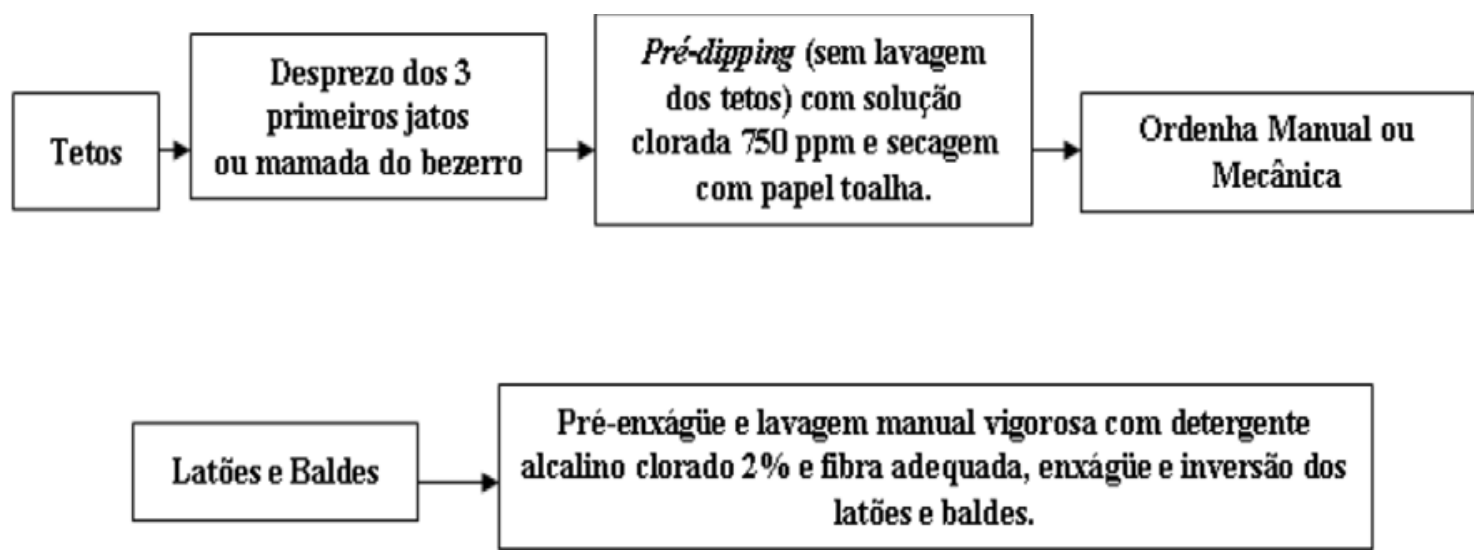

Figura 1. Práticas de higiene aplicadas nas propriedades leiteiras de 19 municípios da região central do Paraná.

\section{Avaliação das práticas}

A eficiência das práticas foi avaliada através de análises para a determinação da carga bacteriana e celular no leite obtido dos latões e tanques de expansão das 46 propriedades. Foram coletadas amostras de leite antes e depois da aplicação das práticas propostas e comparou-se os resultados encontrados.

\section{Colheita e preparo das amostras}

Nas propriedades com ordenha manual foram analisadas $32(69,57 \%)$ amostras de leite, sendo $12(37,5 \%)$ de leite não refrigerado, $5(15,63 \%)$ de tanque de expansão, 7 (21,88\%) de tanque de imersão, 6 (18,75\%) de freezer e $2(6,25 \%)$ de geladeira. Das 14 (30,43\%) amostras das propriedades com ordenha mecânica, 3 (21,43\%) eram de leite não refrigerado, $4(28,57 \%)$ de tanque de expansão, $6(42,86 \%)$ de tanque de imersão e 1 $(7,14 \%)$ do freezer.

As amostras de $100 \mathrm{~mL}$ de leite cru foram acondicionadasemfrascosdepolietilenoesterilizados e adicionadas de duas gotas do conservante azidiol para as amostras destinadas a contagem bacteriana e um comprimido de bronopol (2-bromo-2- nitropropano-1,3-diol) para as amostras destinadas a contagem de células somáticas.
As análises foram realizadas após 24 horas da coleta pelo laboratório do Programa de Análises de Rebanhos Leiteiros da Associação Paranaense dos Criadores Bovinos da Raça Holandesa (PARL/ APCBRH) em Curitiba/PR.

Contagem de células somáticas (CCS) e Contagem bacteriana total (CBT)

Os parâmetros de qualidade considerados foram a CCS, indicativo de sanidade da glândula mamária, e a CBT, indicativo de higiene de ordenha, conforme apontam Fonseca e Santos (2000).

Para a CBT foi utilizado o equipamento BACTOCOUNT - IBC. A CCS foi realizada em contador eletrônico SOMACOUNT $500^{\circledR}$.

\section{Resultados e Discussão}

A CBT e a CCS devem seguir a IN51, onde o máximo permitido para leite cru refrigerado é de 1 milhão UFC/mL e 1 milhão células $/ \mathrm{mL}$, respectivamente (BRASIL, 2002).

Das 46 amostras de leite analisadas, $21(45,65 \%)$ apresentaram CBT acima de 1 milhão UFC/ $\mathrm{mL}$, apresentando média de 2.410.870 UFC/mL. Resultado semelhante foi encontrado por Nero et al. (2005) que estudaram propriedades leiteiras do Rio 
Grande do Sul, Paraná, São Paulo e Minas Gerais e encontraram $48,60 \%$ das amostras com CBT acima de 1 milhão. Bueno et al. (2002), analisaram 20 amostras de leite cru no estado de Goiás e encontram $15(75 \%)$ com contagem acima de 1 milhão UFC/ mL. Em outro estudo, realizado em Santa Maria (RS), Viana et al. (2002) observaram que apenas $17,8 \%$ de leite cru apresentou contagem abaixo do limite estabelecido pela IN51.

Considerando apenas as 32 propriedades com ordenha manual, $14(43,75 \%)$ apresentaram CBT acima de 1 milhão UFC/mL. As maiores médias foram encontradas no leite resfriado em tanques de expansão e em tanques de imersão, com contagens de 3.657 .000 e 2.712.429UFC/mL, respectivamente. Nas propriedades com ordenha mecânica, 7 (50\%) das 14 amostras de leite apresentaram CBT acima de 1 milhão UFC/mL. As maiores médias também foram encontradas em leite resfriado em tanques de expansão e em tanques de imersão, com 8.187.250 e 3.582.667 UFC/mL, respectivamente (Tabela 1). Pinto, Martins e Vanetti (2006), analisando amostras de leite cru refrigerado de tanques coletivos e individuais da região da Zona da Mata Mineira, encontrou CBT variando de 1.400 .000 a 5.500.000 UFC/mL. O resfriamento do leite tornase um problema quando são armazenados leites com alta contagem bacteriana inicial. O processo de refrigeração do leite não impede a multiplicação de algumas bactérias, as psicrotróficas. Estas bactérias conseguem dobrar sua população a cada 20 a 30 minutos e, por isso, o leite deve ser manuseado corretamente, evitando sua contaminação, desde o momento da ordenha até chegar à indústria de laticínios e ao consumidor final (GUERREIRO et al., 2005). A variação da temperatura e o tempo de armazenamento do leite e a higienização inadequada são outros fatores que influenciam na qualidade do leite refrigerado.

Após a implantação das práticas propostas houve uma redução média de $87,90 \%$ na CBT nas propriedades com ordenha manual e $86,99 \%$ nas propriedades com ordenha mecânica. Apenas $2(6,25 \%)$ propriedades com ordenha manual e 2 $(15,22 \%)$ com ordenha mecânica permaneceram com CBT acima de 1 milhão UFC/mL, portanto fora do padrão exigido pela legislação (Tabela 1). A maior eficiência das práticas foi obtida em propriedades com ordenha mecânica e refrigeração em tanque de expansão, onde a redução chegou a 93,95\%. Nas propriedades onde Fagan et al. (2005) aplicaram essas mesmas práticas houve uma redução média de $99,2 \%$ na CBT do leite.

Observou-se que a média da CBT encontrada em propriedades com ordenha mecânica foi em torno de três vezes maior do que a média encontrada em propriedades com ordenha manual, antes e após as práticas, indicando que o nível tecnológico da ordenha não implica, necessariamente, em leite de melhor qualidade e dependendo de como é utilizada, pode ser mais uma fonte de contaminação bacteriana.

Com relação a CCS, a média encontrada antes da aplicação das práticas nas 46 propriedades estudadas foi de 611.913 céls./mL, sendo que 6 (13,04\%) propriedades estavam acima do padrão permitido. Considerando apenas as propriedades com ordenha manual, a média encontrada foi de 607.844 céls./ $\mathrm{mL}$, sendo que $5(15,63 \%)$ das 13 amostras estavam acima de 1 milhão. Lima et al (2006), estudando rebanhos de 13 propriedades do Agreste de Pernambuco, encontraram média de 402.126 céls./mL. Zanela et al. (2006), analisando rebanhos leiteiros no Rio Grande do Sul com ordenha manual e balde ao pé, encontraram médias de 803.000 céls./ mL. Nas propriedades com ordenha mecânica, a média encontrada em nosso trabalho foi de 621.224 céls./mL. Apenas uma (3,13\%) amostra, obtida do tanque de imersão, apresentou contagem acima de 1 milhão. Machado, Pereira e Sarríes (2000) avaliaram 4.785 amostras de leite de tanques de expansão para CCS de rebanhos localizados no estado de São Paulo e sul de Minas Gerais e registraram média de 505.000 céls. $/ \mathrm{mL}$. 
Tabela 1. Resultado das médias da CBT antes e após a aplicação das práticas de higiene nas 46 propriedades leiteiras com ordenha manual e mecânica de 19 municípios da região central do Paraná, entre 2005 e 2006.

\begin{tabular}{|c|c|c|c|c|c|c|c|}
\hline \multicolumn{5}{|c|}{$\begin{array}{l}\text { Ordenha Manual } \\
\text { CBT (UFC/mL) }\end{array}$} & \multicolumn{3}{|c|}{$\begin{array}{c}\text { Ordenha Mecânica } \\
\text { CBT (UFC/mL) }\end{array}$} \\
\hline & $\begin{array}{l}\text { média antes } \\
\text { das práticas* }\end{array}$ & $\begin{array}{l}\text { média após } \\
\text { as práticas* }\end{array}$ & \% Redução & & $\begin{array}{l}\text { média antes } \\
\text { das práticas* }\end{array}$ & $\begin{array}{l}\text { média após } \\
\text { as práticas* }\end{array}$ & \% Redução \\
\hline $\begin{array}{l}\text { leite não } \\
\text { refrigerado }\end{array}$ & 643.083 & 59.000 & 90,83 & $\begin{array}{l}\text { leite não } \\
\text { refrigerado }\end{array}$ & 1.689 .667 & 110.000 & 93,49 \\
\hline expansão & 3.657 .000 & 490.400 & 86,59 & expansão & 8.187 .250 & 495.250 & 93,95 \\
\hline imersão & 2.712 .429 & 330.000 & 87,83 & imersão & 3.582 .667 & 877.500 & 75,51 \\
\hline freezer & 912.333 & 79.000 & 91,34 & freezer & 421.000 & 197.000 & 53,21 \\
\hline geladeira & 351.000 & 124.500 & 64,53 & geladeira & $\ldots$ & $\ldots$ & $\ldots$ \\
\hline Total & 1.598 .906 & 193.531 & 87,90 & Total & 4.266 .786 & 555.214 & 86,99 \\
\hline
\end{tabular}

*as práticas de higiene utilizadas foram: desprezo dos três primeiros jatos de leite, pre-dipping direto com solução clorada $750 \mathrm{ppm}$ em caneca sem refluxo, higienização manual vigorosa de baldes, latões e refrigeradores com detergente alcalino clorado $2 \%$ e fibra macia LT Scotch-brite ou similar e inversão dos latões e baldes e inclinação de refrigeradores para escoamento da água residual.

Após a aplicação das práticas propostas a redução média na CCS foi de $55,65 \%$ - exceto do tanque de expansão onde houve um aumento da contagem de $27,12 \%$ - em propriedades com ordenha manual e $51,85 \%$ em propriedades com ordenha mecânica. Após as práticas, das 46 propriedades estudadas,
$2(6,25 \%)$ propriedades com ordenha manual e nenhuma com ordenha mecânica apresentaram valores acima de 1 milhão céls./mL (Tabela 2). O maior impacto das práticas foi observado em propriedades com ordenha manual e refrigeração em tanque de expansão onde a redução chegou a $63,73 \%$.

Tabela 2. Resultado das médias da CCS antes e após a aplicação das práticas de higiene nas 46 propriedades leiteiras com ordenha manual e mecânica de 19 municípios da região central do Paraná, entre 2005 e 2006.

\begin{tabular}{|c|c|c|c|c|c|c|c|}
\hline \multicolumn{5}{|c|}{$\begin{array}{l}\text { Ordenha Manual } \\
\text { CCS (céls./mL) }\end{array}$} & \multicolumn{3}{|c|}{$\begin{array}{l}\text { Ordenha Mecânica } \\
\text { CCS (céls./mL) }\end{array}$} \\
\hline & $\begin{array}{l}\text { média antes } \\
\text { das práticas* }\end{array}$ & $\begin{array}{l}\text { média após } \\
\text { as práticas* }\end{array}$ & \% Redução & & $\begin{array}{l}\text { média antes } \\
\text { das práticas* }\end{array}$ & $\begin{array}{l}\text { média após } \\
\text { as práticas* }\end{array}$ & \% Redução \\
\hline $\begin{array}{l}\text { leite não } \\
\text { refrigerado }\end{array}$ & 601.250 & 272.000 & 54,76 & $\begin{array}{l}\text { leite não } \\
\text { refrigerado }\end{array}$ & 553.333 & 255.333 & 53,86 \\
\hline expansão & 708.000 & 256.800 & 63,73 & expansão & 581.000 & 286.750 & 50,65 \\
\hline imersão & 672.714 & 855.143 & $-27,12$ & imersão & 680.833 & 359.000 & 47,27 \\
\hline freezer & 554.000 & 349.333 & 36,94 & freezer & 628.000 & 121.000 & 80,73 \\
\hline geladeira & 335.000 & 110.000 & 67,16 & geladeira & $\ldots$ & $\ldots$ & $\ldots$ \\
\hline Total & 607.844 & 401.563 & 33,94 & Total & 621.224 & 299.143 & 51,85 \\
\hline
\end{tabular}

*as práticas de higiene utilizadas foram: desprezo dos três primeiros jatos de leite, pre-dipping direto com solução clorada $750 \mathrm{ppm}$ em caneca sem refluxo, higienização manual vigorosa de baldes, latões e refrigeradores com detergente alcalino clorado $2 \%$ e fibra macia LT Scotch-brite ou similar e inversão dos latões e baldes e inclinação de refrigeradores para escoamento da água residual. 
A redução mais significante para $\mathrm{CBT}$ do que para CCS encontrada neste trabalho se deve ao fato de que as práticas propostas agem diminuindo a contaminação microbiana dos tetos, utensílios e equipamentos de ordenha, melhorando a qualidade microbiológica do leite e reduzindo o aparecimento de novos casos de mastite. As CCS também não se apresentavam tão altas, havendo menos a reduzir. Ainda, com a aplicação das práticas a redução da CBT é imediata, sentindo-se os resultados já na primeira ordenha, enquanto a CCS vai diminuindo ao longo do tempo, após a cura dos casos existentes e prevenção de novos casos.

\section{Conclusão}

As práticas propostas são de simples incorporação na rotina de ordenha, e contribuíram significativamente para a melhoria da qualidade do leite em quaisquer das condições de tecnificação estudadas. Práticas simples, como o desprezo dos três primeiros jatos de leite, lavagem dos utensílios de ordenha (latões, baldes, teteiras) com detergente alcalino clorado $2 \%$, pré-dipping com solução clorada 750 ppm em caneca sem refluxo e eliminação da água residual dos utensílios de ordenha foram suficientes para a adequação do leite fluido à IN51.

\section{Referências}

BELOTI, V.; BARROS, M. A. F.; NERO, L. A.; SOUZA, J. A.; SANTANA, E. H. W.; BALARIN, O.; CURIAKI, Y. Avaliação da qualidade do leite cru comercializado em Cornélio Procópio, Paraná. Controle do consumo e da comercialização. Semina: Ciências Agrárias, Londrina, v. 20, n. 1, p. 12-15, 1999.

BRASIL. Ministério da Agricultura Pecuária e Abastecimento. Instrução Normativa № 51. Aprovado em 18 de setembro de 2002. Dispões sobre os regulamentos técnicos aplicados ao leite cru e pasteurizado. Diário Oficial [da] República Federativa do Brasil, Brasília, 2002. n. 183.

BUENO, V. F. F.; MESQUITA, A. J.; NICOLAU, E. S.; MANSUR, J. R. G.; NEVES, R. B. S. Parameters of microbiological quality of raw milk and water in dairy farms in Goiás state, Brazil. In: CONGRESSO
PANAMERICANO DE QUALIDADE DO LEITE E CONTROLE DE MASTITE, 2., 2002, Ribeirão Preto. Anais eletrônicos... São Paulo: Instituto Fernando Costa, 2002. CD-ROM

BUENO, V. F. F.; MESQUITA, A. J.; OLIVEIRA, J. P.; NICOLAU, E. S.; OLIVEIRA, A. N.; NEVES, R. B. S.; MANSUR, J. R. G. Influência da temperatura de armazenamento e o sistema de utilização de tanque de expansão sobre a qualidade microbiológica do leite cru. Revista Higiene Alimentar, São Paulo, v. 18, n. 124, p. 62-67, set. 2004.

CORDEIRO, C. A. M.; CARLOS, L. A.; MARTINS, M. L. L. Qualidade microbiológica do leite pasteurizado tipo C, proveniente de micro-usinas de Campos dos Goytacazes, RJ. Revista Higiene Alimentar, São Paulo, v. 16, n. 92/93, p. 41-44, jan./fev. 2002.

FAGAN, E. P.; BELOTI, V.; BARROS, M. A. F.; MULLER, E. E.; NERO, L. A.; SANTANA, E. H. W.; MAGNANI, D. F.; VACARELLI, E. R.; SILVA, L. C.; PEREIRA, M. S. Avaliação e implantação de boas práticas nos principais pontos de contaminação microbiológica na produção leiteira. Semina: Ciências Agrárias, Londrina, v. 26, n. 1, p. 83-92, jan./mar. 2005.

FONSECA, L. F. L.; SANTOS, M. V. Qualidade do leite e controle da mastite. São Paulo: Lemos, 2000.

FRANCO, B. D. G. M.; LANDGRAF, M. Microrganismos indicadores. In: . Microbiologia dos Alimentos. São Paulo: Ateneu, 1996. p. 27-31.

FREITAS, J. A.; OLIVEIRA, J. P.; SUMBO, F. D.; CARVALHO, R. C. F.; AMORIM JÚNOR, B.; MORAES, R. J.; MARINHO, R.; SARRAF, K. A. Características físico-químicas e microbiológicas do leite fluido exposto ao consumo na cidade de Belém, Pará. Revista Higiene Alimentar, São Paulo, v. 16, n. 16, p. 89-96, set. 2002.

GUERREIRO, P. K.; MACHADO, M. R. F.; BRAGA, G. C.; GASPARINO, E.; FRANZENER, A. S. M. Qualidade microbiológica de leite em função de técnicas profiláticas no manejo de produção. Ciências Agrotécnicas, Lavras, v. 29, n. 1, p. 216-222, jan./fev. 2005.

INSTITUTO BRASILEIRO DE GEOGRAFIA E ESTATÍSTICA - IBGE. Indicativos agropecuários. Disponível em: <http://www.ibge.gov.br $>$. Acesso em: maio 2007.

LIMA, M. G. C.; SENA, M. J.; MOTA, R. A.; MENDES, E. S.; ALMEIDA, C. C.; SILVA, R. P. P. E. Contagem de células somáticas e análises físico-químicas e microbiológicas do leite cru tipo c produzido na região agreste do estado de Pernambuco. Arquivos do Instituto Biológico, São Paulo, v. 73, n. 1, p. 89-95, jan./mar. 2006. 
MACHADO, P. F.; PEREIRA, A. R.; SARRÍES, G. A. Composição do leite de tanques de rebanhos brasileiros distribuídos segundo sua contagem de células somáticas. Revista Brasileira de Zootecnia, Viçosa, v. 29, n. 6, p. 1883-1886, 2000.

NASCIMENTO, M. S.; SOUZA, P. A. Estudo da correlação linear entre a contagem padrão em placa, a contagem de psicrotróficos e a prova da redutase em leite cru resfriado. Revista Higiene Alimentar, São Paulo, v. 16, n. 97, p. 81-87, jun. 2002.

NERO, L. A.; MATTOS, M. R.; BELOTI, V.; BARROS, M. A. F.; PINTO, J. P. A. N.; ANDRADE, N. J.; SILVA, W. P.; FRANCO, B. D. G. M. Leite cru de quatro regiões leiteiras brasileiras: perspectivas de atendimento dos requisitos microbiológicos estabelecidos pela instrução normativa 51. Ciência e Tecnologia de Alimentos, Campinas, v. 25, n. 1, p. 191-195, jan./mar. 2005.

PHILPOT, W. N.; NICKERSON, S. C. Mastitis: counter attack. Naperville: Babson Bros, 1991.

PINTO, C. L. O.; MARTINS, M. L.; VANETTI, M. C. D. Qualidade microbiológica de leite cru refrigerado e isolamento de bactérias psicrotróficas proteolíticas. Ciência e Tecnologia de Alimentos, Campinas, v.26, n. 3, p. 645-651, jul./set. 2006.

RENEAU, J. K. Effective use of dairy herd improvement somatic cell counts in mastitis control. Journal of Dairy Science, Champaign, v. 69, n. 6, p. 1708-1720, 1986.
RIBEIRO, M. E. R.; STUMPF JÚNIOR, W.; BUSS, H. Qualidade de leite. In: BITENCOURT, D.; PEGORARO, L. M. C.; GOMES, J. F. Sistemas de pecuária de leite: uma visão na região de Clima Temperado. Pelotas: Embrapa Clima Temperado, 2000. p. 175-195.

SANTANA, E. H. W.; BELOTI, V.; BARROS, M. A. F. Microrganismos psicrotróficos em leite. Revista Higiene Alimentar, São Paulo, v. 15, n. 88, p. 27-33, set. 2001.

SANTANA, E. H. W.; BELOTI, V.; BARROS, M. A. F.; MORAES, L. B.; GUSMÃO, V. V.; PEREIRA, M. S. Contaminação do leite em diferentes pontos do processo de produção: I. Microrganismos aeróbios mesófilos e psicrotróficos. Semina: Ciências Agrárias, Londrina, v. 22, n. 2, p. 145-154, jul./dez. 2001.

VIANA, L. R.; HENZEL, A.; SPRICIGO, D. A.; LOGUERCIO, A. P.; WITT, N. M.; VARGAS, A. C. Qualidade do leite in natura recebido pela usina escola de laticínios da UFSM. In: CONGRESSO BRASILEIRO DE MEDICINA VETERINÁRIA, 29., 2002, Gramado. Anais... Gramado: SBMV, 2002. p. 22-22.

ZANELA, M. B.; FISCHER, V.; RIBEIRO, M. E. R.; STUMPF JUNIOR, W.; ZANELA, C.; MARQUES, L. T.; MARTINS, P. R. G. Qualidade do leite em sistemas de produção na região Sul do Rio Grande do Sul. Pesquisa Agropecuária Brasileira, Brasília, v. 41, n. 1, p. 153-159, jan. 2006. 